\title{
Diabetes management in Australian rural aged care facilities: A cross-sectional
}

\section{audit}

\author{
Khalil $H^{1}$. Tan, L. ${ }^{2}$ George J.2
}

1. Monash University, Faculty of Medicine, Nursing and Health Sciences, School of Rural Health, Department of Rural and Indigenous Health, Australia

2. Monash University, Faculty of Pharmacy and Pharmaceutical Sciences, Australia

RESEARCH

Please cite this paper as: Khalil H Tan, L George J. Diabetes management in Australian rural aged care facilities: a cross sectional audit. AMJ 2012, 5, 11, 575-.580. http://doi.org/10.21767/AMJ.2012.1411

\section{Corresponding Author:}

Name Hanan Khalil

Address PO Box 973, Moe, Vic 3825

Email: hanan.khalil@monash.edu

\section{Abstract}

\section{Background}

There is gap in the literature regarding the current practice of diabetes management of the elderly in Australia and its compliance with available Australian diabetes practice guidelines.

Aims

The aims of this study were to describe the pharmacological management of elderly residents with diabetes living in aged care facilities and to identify areas for improvement in the current management as recommended by the current diabetes management guidelines in Australia.

\section{Method}

Residents with diabetes from three rural aged care facilities were identified by nursing staff. A cross--sectional medical record audit was carried out to obtain data of residents diagnosed with diabetes.

Thirty-four medical records were audited from three aged care facilities. Data including demographics, medical histories and medications were collected and analysed.

\section{Results}

This study had two key findings; Firstly, it showed that about a third of residents with type 2 diabetes are managed with diet only. Secondly, of the residents who are managed with medications, less than half of those audited (41\%) were managed according to the current diabetes guidelines in terms of pharmacological treatment which included anti-hypertensive, lipid lowering and anti-.- platelet therapies. Of those patients with a history of CVD, all were receiving an antihypertensive medication, $71 \%$ were not managed for their lipids and $20 \%$ were not on any prophylactic antiplatelet therapy.

Conclusion

Management of patients with diabetes living in rural aged care facilities is inconsistent with the current management guidelines. Educational interventions targeting health professionals and patients might be beneficial to increase compliance with the current diabetes guidelines.

\section{Key Words}

Type 2 diabetes, Pharmacological management, diabetes guidelines, elderly, aged care facilities

\section{What this study adds:}

- $\quad$ There is a gap in the literature regarding diabetes management of elderly Australians living in aged care facilities and the extent to which current management complies with evidence--based practice guidelines.

- This study highlighted that less than half of the residents audited were therapeutically managed according to the current diabetes guidelines which included anti-hypertensive, lipid lowering and anti-platelet therapies. 
- Educational interventions targeting health professionals and patients might be beneficial to increase compliance with the current diabetes practice guidelines).

\section{Background}

Management of type 2 diabetes focuses on lifestyle modification, maintaining normal blood sugar level and reducing cardiovascular risk factors. ${ }^{1}$ Patients with type 2 diabetes have a two to fourfold increase in the risk of mortality from cardiovascular disease (CVD). ${ }^{2,3}$ Several CVD risk factors including hyperglycaemia, hypertension and dyslipidaemia were identified in individuals with type 2 diabetes in the United Kingdom Prospective Diabetes Study (UKPDS). ${ }^{4}$ Elderly with diabetes who live in residential aged care facilities often have a number of age--specific issues such as decreased levels of independence, impaired mobility and dexterity, inadequate social support, reduced capability for self-care, and co-morbidities. ${ }^{5-9}$ These will eventually impact on diabetes management, glycaemic control and subsequent health related outcomes. ${ }^{10}$

The current Australian type 2 diabetes management guidelines ${ }^{6}$ for the elderly specify treatments targets for various parameters including $\mathrm{HbA} 1 \mathrm{c}(<7 \%)$, blood pressure $(<140 / 90 \mathrm{mmHg}$ ) and lipid control (LDL $<2.5 \mathrm{mmol} / \mathrm{L}$, $\mathrm{TG}<2.0 \mathrm{mmol} / \mathrm{L}$ ) to prevent and reduce diabetes complications. These targets are slightly different to the general adults to allow for age-related differences in body function. ${ }^{6}$

The above targets are based on evidence from large prospective intervention studies which clearly demonstrate that combination therapy aimed at controlling glucose, blood pressure, lipids and fibrinolysis significantly reduces micro and macrovascular morbidity and mortality in patients with type 2 diabetes. ${ }^{5,11}$ Older adults with diabetes are at greater risk of other common geriatric syndromes such as depression, cognitive impairment, urinary incontinence, falls and persistent pain than their counterparts. ${ }^{12}$ Moreover, several barriers impede diabetes management in the elderly and include: perception of ageing, physical activity, co--morbidities, nutritional status, learning memory and capacity, mental status, social status and access and equity. Taking all of the above mentioned factors into consideration and coming up with recommendations to suit the different individuals is a challenging task for clinicians involved in caring for the elderly with diabetes. ${ }^{13-15}$ There is a gap in the literature regarding diabetes management of elderly Australians living in aged care facilities and the extent to which the management complies with the current evidence---based practice guidelines.

\section{The aims of this project were to:}

1. describe the management of diabetes in a group of elderly residents living in aged care facilities in rural Australia; and

2. identify areas for improvement in the current management after making comparisons with the current diabetes management guidelines in Australia.

\section{Methods and data collection}

Residents with diabetes from three rural aged care facilities were identified by nursing staff. A cross--sectional medical record audit was carried out to obtain data of residents diagnosed with diabetes from the participating age care facilities.

Data collected included: age (years), gender, co-morbidities, diet, anti-- diabetic medication type and dose (if prescribed), antihypertensive medication type and dose (if prescribed), lipid lowering medication type and dose (if prescribed), anti-. platelet therapy (if prescribed), HbA1c (\%), total cholesterol $(\mathrm{mmol} / \mathrm{L}), \mathrm{LDL}(\mathrm{mmol} / \mathrm{L}), \mathrm{HDL}(\mathrm{mmol} / \mathrm{L}), \mathrm{TG}$ ( $\mathrm{mmol} / \mathrm{L})$ and other pathology results.

\section{Inclusion /Exclusion Criteria}

Only residents with type 2 diabetes and on pharmacological treatment who provided written consent were included in this study. Residents with type 1 diabetes and type 2 diabetes controlled by diet only were excluded from our study.

\section{Data analysis}

Descriptive statistics was used to analyse the residents' demographic, medical conditions and medication management. Data analysis was performed using Microsoft Office Excel. Ethics approval was obtained from Monash University Human Research Ethics Committee.

\section{Results}

The three aged care facilities included in this study had a total of 236 residents, 37 (16\%) of whom were identified with diabetes. Thirty-four of these residents gave consent to have their histories audited by the researchers. The remainder three residents were not able to give consent due to cognitive disabilities. Five (15\%) residents had type 1 diabetes and 29 (85\%) were diagnosed with type 2 diabetes. There were 12 (35\%) residents with type 2 diabetes managed by diet only. Only data from elderly residents with 
type 2 diabetes who were managed by medications $(n=17)$ are included in this report.

Demographic characteristics of the residents are displayed in Table 1. The mean age of the residents was 86 years (range 75-94 years). Their mean HbA1c was $7.4 \%$ (range $6.5-8.0 \%$ ). The majority of the residents (76\%) were female.

Table 1: Demographic characteristic of the sample $(n=17)$

\begin{tabular}{|l|l|}
\hline Characteristic at Diagnosis & Mean \pm SD or $\mathrm{n}(\%)$ \\
\hline Female & $13(76)$ \\
\hline Age (yrs) & $86.0 \pm 5.1$ \\
\hline $\begin{array}{l}\text { HbA1c (\%) } \\
\text { (mL/min) }\end{array}$ & $7.4 \pm 0.5$ \\
\hline $\begin{array}{l}\text { Urea (mmol/L) } \\
\text { Creatinine (mmol/L) }\end{array}$ & $53.3 \pm 16.0$ \\
\hline $\begin{array}{l}\text { History of cardiovascular } \\
\text { disease }\end{array}$ & $15.0(88)$ \\
\hline $\begin{array}{l}\text { Number of medical } \\
\text { conditions }\end{array}$ & $6.0 \pm 2.4$ \\
\hline $\begin{array}{l}\text { Number of regular } \\
\text { medications }\end{array}$ & $9.0 \pm 4.4$ \\
\hline $\begin{array}{l}\text { Number of 'prn' } \\
\text { medications }\end{array}$ & $3.0 \pm 2.2$ \\
\hline
\end{tabular}

The prevalence of CVDs among residents were as follows: CVD (47\%), heart failure (20\%), ischaemic heart disease (20\%), myocardial infarction (13\%), stroke (7\%) and hypertension (47\%). The mean number of other medical conditions was 6.0. The most common co morbidities were hypertension (59\%) followed by dyslipidaemia (35\%), osteoporosis (35\%) and osteoarthritis (35\%). On average the residents were using nine regular medications and three 'prn' (use when needed) medicines.

Local pathology laboratories were contacted to obtain the required results as well as results from the residents medical histories were checked. No resident had complete pathology results. Only 10 (59\%) had HbA1c, 4 (24\%) residents had lipid levels, 10 (59\%) had serum urea, 12 (71\%) had serum creatinine and 11 (65\%) had estimated Glomerular Filtration Rate results.

\section{Glucose management}

Almost half of the audited residents $n=9$ (53\%) were on anti-. diabetic medication. Their mean $\mathrm{HbA1c}$ was 7.5. Seven (42\%) of those using dual therapy had a mean HbA1c of 7.6 (Table 2). One resident was on three anti-diabetic agents, but had adequate glycaemic control. Of the residents who had inadequate control of $\mathrm{HbA} 1 \mathrm{c}$ as recommended by the guideline $(n=7)$, six $(86 \%)$ were managed by one antidiabetic agent (metformin). The most commonly prescribed anti-diabetic agents were sulphonylureas (gliclazide median dose/day 60mg, glipizide mean dose/day 5mg) and metformin (median dose/day 1000mg), followed by insulin (glargine, median dose/day 20 units) and sitagliptin (median dose/day 100mg).

Table 2: Management of hyperglycaemia

\begin{tabular}{|l|l|l|l|}
\hline & $N(\%)$ & $\begin{array}{l}\text { Mean HbA1c } \\
(\%) \pm \text { SD } \\
(n=10)\end{array}$ & $\begin{array}{l}\text { Subset with } \\
\text { HbA1c >7\% } \\
n(\%)(n=7)\end{array}$ \\
\hline On 1 agent & $9(53)$ & $7.5 \pm 0.5$ & $6(86)$ \\
\hline On 2 agents & $7(42)$ & $7.6 \pm 0.1$ & $1(14)$ \\
\hline On 3 agents & $1(6)$ & 6.7 & 0 \\
\hline
\end{tabular}

\section{Blood pressure management}

All the participants $(n=17)$ were on at least one antihypertensive agent. Angiotensin-converting enzyme inhibitors (ACEI) were the most common agent prescribed followed by angiotensin receptor blockers (ARB), beta blockers, calcium channel blockers and alpha blockers (Table 3).

Table 3: management of blood pressure

\begin{tabular}{|l|l|}
\hline $\begin{array}{l}\text { Type of anti-hypertensive } \\
\text { agent }\end{array}$ & N \\
\hline ACEI & 8 \\
\hline ARB & 7 \\
\hline Others & 15 \\
\hline
\end{tabular}

Note: Some patients were on more than one anti-.

hypertensive agent

\section{Lipid management}

Ten (59\%) residents were taking one lipid lowering agent.

Seven (41\%) residents were not receiving lipid--lowering 
therapy, of whom five (71\%) had a history of CVD. The most commonly prescribed lipid lowering drug was simvastatin.

\section{Prophylactic anti-.platelet therapy}

Thirteen (76\%) residents were taking at least one anti-. platelet agent and 8 (62\%) had a history of CVD. The primary pharmacological agents prescribed were aspirin, all at standard dose of $100 \mathrm{mg} /$ day, followed by clopidogrel, heparin and direct thrombin inhibitors (Table 4).

Table 4: Type of anti-. platelet therapy $(n=13)$

\begin{tabular}{|l|l|}
\hline Type of anti-- platelet agent & $\mathrm{N}(\%)$ \\
\hline Aspirin & $9(69)$ \\
\hline Clopidogrel & $2(15)$ \\
\hline Heparin & $1(8)$ \\
\hline Direct thrombin inhibitors (Pradaxa) & $1(8)$ \\
\hline
\end{tabular}

Differences between practice guidelines and current management of patients with type 2 diabetes

Of the 17 resident records audited, seven (41\%) had no $\mathrm{HbA} 1 \mathrm{c}$ results recorded in the notes. Only two (12\%) from the cohort achieved optimal targets for glucose management, leaving 8 (47\%) not controlling glucose levels as recommended by the current Australian guideline. ${ }^{6}$

No resident had a complete series of $\mathrm{HbA} 1 \mathrm{c}$ results, blood pressure readings, lipid levels and renal function tests in a specific time frame as recommended by the guidelines.

Of those patients with a history of CVD, all were receiving an anti-hypertensive medication, $71 \%$ were not managed for their lipids and $20 \%$ were not on any prophylactic anti-. platelet therapy.

\section{Discussion}

This study found that about a third of residents with type 2 diabetes are managed with diet only. These results are consistent with another finding by Hippisley-.Cox et $\mathrm{al}^{17}$ that found that $31 \%$ of 7970 diabetics from 42 general practices were being managed with diet only for their diabetes. People with diabetes might be effectively managed with diet only, but there needs to be better routine monitoring and more intensive therapy if sugar control, blood pressure or cholesterol is not optimum. There is clearly a considerable scope for improving the care received by these patients as more than a third of the residents were managed by diet only. This report might encourage doctors to look at patients on diet only treatment and reconsider how they are managed in the long run to prevent complications. $^{17}$

Another key finding from this study found that the management of type 2 diabetes in patients living in rural aged care facilities is inconsistent with the current management guideline, which warrants the attention of health professionals. This study highlighted that less than half of the residents audited (41\%) were therapeutically managed according to the current diabetes guideline which included anti-hypertensive, lipid lowering and anti-platelet therapies.

Current evidence-"-based guidelines for CVD prevention in diabetes focus on the ABCDs of CVD management in diabetes namely anti-platelet therapy, blood pressure control, cholesterol management, and diabetes/glucose management. ${ }^{16}$ Achieving this goal requires a concentrated focus on improving the management of diabetes and in targeting prevention of macrovascular complications. The results of this audit reflect the low implementation rate of the current evidence--based guidelines.

Barriers to the low uptake of evidence include; lack of referral pathways, uncertainty about the full benefit of these treatments in this group of elderly and the lack of awareness of the current guidelines. ${ }^{16}$

Management of elderly is very challenging to clinicians due to several barriers. Elderly patients are not a homogenous group due to the number of co-morbidities they have, the decline in organ function, the multiple medications they are on, the social issues surrounding them and the dubious cost benefit associated with some of the available treatments.

There is a great scope for improving the health status of these individuals by increasing practitioner awareness of the current practice guidelines, and offering patients affiliation with a diabetic treatment centre. The latter approach may be useful in rural and remote areas when accessibility to health professionals is a challenge and also access to health education and comprehensive care for newly diagnosed individuals is scarce.

Limitations of this study include the cross--sectional design of the study. The study did not examine the duration of treatment and whether the full benefit of treatment had been achieved at the time of the study and the small sample size. We also acknowledge that patient and carer wishes had to be taken into account before starting treatments and this might have contributed to the discrepancies with the guidelines. 


\section{Conclusion}

This report highlights gaps in the management of diabetes in older adults living in aged care facilities. Educational interventions targeting health professionals and patients might be beneficial to increase compliance with the current diabetes practice guidelines.

\section{References}

1. Centres for Disease Control and Prevention (CDC). National diabetes fact sheet: General information and national estimates on diabetes in the United States, 2007. Atlanta, GA: CDC, 2008.

2. Knowler WC, Fowler SE, Hamman RF, Christophi CA, Hoffman HJ, Brenneman AT, et al for the Diabetes Prevention Program Research Group. Ten-year follow up of diabetes incidence and weight loss in the Diabetes Prevention Program Outcomes Study. Lancet. 2009 Nov 14;374(9702):1677--86.

3. Diabetes Control and Complications Trial Research Group. The effect of intensive treatment of diabetes on the development and progression of long-term complications in insulin--dependent diabetes mellitus. N Engl J Med. 1993 Sep 30;329(14):977-86.

4. UK Prospective Diabetes Study Group (UKPDS). Intensive blood glucose control with sulphonylureas or insulin compared with conventional treatment and risk of complications in patients with type 2 diabetes (UKPDS 33). Lancet. 1998 Sep 12;352(9131):837-.53.

5. Dornan TL, Peck GM, Dow JDC, Tattersall RB. A community survey of diabetes in the elderly. Diabet Med. 1992 Nov;9(9):860- 5.

6. Bolger $\mathrm{H}$, Harries $\mathrm{P}$, Mann L, Philips $\mathrm{P}$, Webster $\mathrm{C}$. Diabetes management in general practice: Guideline for Type 2 Diabetes. Diabetes Australia; 2011.

7. Neil HAW, Thompson AV, Thorogood M, Fowler GH, Mann JI. Diabetes in the elderly: The Oxford Community Diabetes Study. Diabet Med. 1989 Sep-Oct;6(7):608--13.

8. Dunstan DW, Zimmet PZ, Welborn TA, Shaw J, De Courten $\mathrm{M}$, Cameron $\mathrm{A}$, et al. The rising prevalence of diabetes and impaired glucose tolerance: the Australian diabetes obesity and lifestyle study. Diabetes Care. 2002 May;25(5):829--34.

9. Vokonas PS, Kannel WB. Diabetes mellitus and coronary heart disease in the elderly. Clin Geriatr Med. 1996 Feb;12(1):69--78.

10. Duckworth W, Abraira C, Moritz T, Reda D, Emanuele N, Reaven PD, et al, for the VADT Investigators. Glucose control and vascular complications in veterans with type 2 diabetes. N Engl J Med. 2009 Jan 8;360(2):129-39.

11. Patel A, MacMahon S, Chalmers J, Neal B, Billot L, Woodward $\mathrm{M}$, et al, for the ADVANCE Collaborative Group. Intensive blood glucose control and vascular outcomes in patients with type 2 diabetes. N Engl J Med. 2008 Jun 12;358(24):2560--72.

10. Nathan DM, Clearly PA, Backlund JY, Genuth SM, Lachin JM, Orchard TJ et al for the DCCT/EDIC Study Research Group. Intensive diabetes control and cardiovascular disease in patients with type I diabetes. N Engl J Med. 2005 Dec 22;353(25):2643--53.

11. Selvin E, Marinopoulos S, Berkenblit G, Rami T, Brancati $F$, Powe NR et al. Meta-analysis: glycosylated hemoglobin and cardiovascular disease in diabetes mellitus. Ann Intern Med. 2004 Sep 21;141(6):421-31.

12. American Diabetes Association. Standards of medical care in diabetes - 2010. Diabetes Care. 2010 Jan;33 Suppl 1:S11-61.

12. Khalil $H$. Prescribing in the elderly: Ethical considerations. Aust J Prim Health. 2011;17(1):2-3.

13. Weaver WD, Litwin PE, Martin JS, Kudenchuk PJ, Maynard C, Eisenberg MS, et al. Effect of age on use of thrombolytic therapy and motality in acute myocardial infarction. J Am Coll Cardiol. 1991 Sep;18(3):657--62.

14. Australian Diabetes Educators Association. Guidelines for the Management and Care of Diabetes in Elderly; 2003.

15. Feldman SM, Rosen R, Destasio J. Status of diabetes management in the nursing home setting in 2008: A retrospective chart review and epidermiology study of diabetic nursing home residents and nursing home initiatives in diabetes management. J Am Med Dir Assoc. 2009 Jun;10(5):354-60.

16. Williams MA, Fleg JL, Ades PA et al. Secondary prevention of coronary heart disease in the elderly (with emphasis on patients $>75$ years of age). Circulation. 2002 Apr 9;105(14):1735--43.

17. Hippisley-Cox J, Pringle M. Prevalence, care, and outcomes for patients with diet controlled diabetes in general practice: cross sectional survey. Lancet 2004; 363: 423-28.

\section{ACKNOWLEDGEMENTS}

We would like to thank the staff and residents of the participating nursing care homes who have been enthusiastic in their involvement and without whom the project would not have been possible

\section{PEER REVIEW}

Not commissioned. Externally peer reviewed

\section{CONFLICTS OF INTEREST}

The authors declare that they have no competing interests. 
Australasian Medical Journal [AMJ 2012, 5, 11, 575--580]

\section{FUNDING}

No funding was attached to this study.

\section{ETHICS COMMITTEE APPROVAL}

Monash University, Human Research office, approval reference

number: $\quad$ CF11/1885

2011001064-Diabetes

management in the elderly. 